\title{
Light fine-grained fibrous concrete for small architectural forms
}

\author{
Albina Baranova ${ }^{1, *}$, Margarita Badenikova ${ }^{1}$, Pavel Shustov ${ }^{2}$, Christina Rudykh $^{1}$, and Anna \\ Bobrova $^{1}$ \\ ${ }^{1}$ Angarsk State Technical University, Department of Industrial and Civil Engineering, 665835, 60 \\ Tchaikovsky str., 60, Angarsk, Russia \\ ${ }^{2}$ Irkutsk National Research Technical University, Department of Construction Production, 664074, \\ Lermontova str., 83, Irkutsk, Russia
}

\begin{abstract}
The selection of the composition of a highly mobile concrete mixture for manufacturing small architectural forms has been performed, and the strength characteristics of light fine-grained fibrous concrete have been studied. It has been experimentally established that the optimal ratio of the Portland cement to microsilica is 1: 1 . The introduction of basalt fiber in the amount of $0.5 \%$ of the mass of solids contributes to the increase in bending strength of fine-grained concrete to $70 \%$.
\end{abstract}

The construction process involves working not only with heavy structural elements, but also with decorative concrete products designed for decoration and decoration of facades and building interiors, and used as small architectural forms.

Small architectural forms (SAF) have a great impact on the emotional state of a person. Their use allows to fill the empty space in the room or on the ground, embodying many ideas architects and designers have.

SAF specificity is the production of thin-walled products of complex configuration with an abundance of small elements. This makes it difficult to use hard concrete mixes. The use of highly movable (cast) concrete mixtures based on traditional materials contradicts the need to ensure strength and durability [1].

The analysis of the literature sources [1-21] made it possible to establish that the use of industrial by-products and dispersed-reinforcing additives in fine-grained concretes makes it possible to increase their strength characteristics.

The aim of the paper is to select the composition of a highly mobile concrete mixture for the preparation of light fine-grained fibrous concrete with increased strength characteristics.

The following materials were used in the studies:

- Portland cement CEM II / A-III 32.5B (PC 400 D20) with a bulk density of $\rho_{\mathrm{n}}=880$ $\mathrm{kg} / \mathrm{m}^{3}$ being produced by the "Angarskcement" JSC;

- White cement of the company "Cimsa" CEM I 52,5 R (PC 600) with a bulk density of $\rho_{\mathrm{n}}=1440 \mathrm{~kg} / \mathrm{m}^{3}$ (Turkey);

- Microsilica from filters of dust collectors made by the Silicon JSC with bulk density of $\rho_{\mathrm{n}}=600 \mathrm{~kg} / \mathrm{m}^{3}$;

* Corresponding author: baranova2012aa@mail.ru 
- Chalk MTD-2 with bulk density of $\rho_{\mathrm{n}}=525 \mathrm{~kg} / \mathrm{m}^{3}$ (Belgorod region);

- Chalk CALCITEC V / 40S with a bulk density of $\rho_{\mathrm{n}}=875 \mathrm{~kg} / \mathrm{m}^{3}$ (Italy);

- Hyperplasticizer based on polycarboxylates "MC-Power-Flow-3100" with a density of $1.09 \mathrm{~g} / \mathrm{cm}^{3}$ (Germany);

- Basalt fiber "Vulcan" (Perm city).

The research method was as follows. The concrete mix was kneaded by hand. The water ratio was chosen in such a way as to ensure the uniform mobility of concrete mixtures with different component ratios. It is known from the previous work [22] that, due to the high water demand of microsilica, it is expedient to use it together with plasticizing additives. The amount of hyperplasticizer was taken constant. Compositions of concrete mixtures made on Portland cement CEM II / A-III 32.5B (PC 400 D20) are listed in Table 1.

Table 1. Compositions of fine-grained concretes.

\begin{tabular}{|c|c|c|c|c|c|c|}
\hline \multirow{2}{*}{$\begin{array}{c}\text { No. } \\
\text { composition }\end{array}$} & \multicolumn{7}{|c|}{$\begin{array}{c}\text { Solids content, \% by weight } \\
\text { D0 }\end{array}$} & MK & $\begin{array}{c}\text { Chalk } \\
\text { MTD-2 }\end{array}$ & $\begin{array}{c}\text { Chalk CALCITEC } \\
\text { V/40S }\end{array}$ & Water & $\begin{array}{c}\text { Hyperplastici } \\
\text { zer }\end{array}$ \\
\hline 1 & 30 & 70 & - & - & 0,62 & 0,002 \\
\hline 2 & 40 & 60 & - & - & 0,61 & 0,002 \\
\hline 3 & 50 & 50 & - & - & 0,6 & 0,002 \\
\hline 4 & 30 & 65 & 5 & - & 0,61 & 0,002 \\
\hline 5 & 40 & 55 & 5 & - & 0,6 & 0,002 \\
\hline 6 & 50 & 45 & 5 & - & 0,59 & 0,002 \\
\hline 7 & 30 & 60 & 10 & - & 0,61 & 0,002 \\
\hline 8 & 40 & 50 & 10 & - & 0,6 & 0,002 \\
\hline 9 & 50 & 40 & 10 & - & 0,58 & 0,002 \\
\hline 10 & 30 & 65 & - & 5 & 0,61 & 0,002 \\
\hline 11 & 40 & 55 & - & 5 & 0,6 & 0,002 \\
\hline 12 & 50 & 45 & - & 5 & 0,58 & 0,002 \\
\hline 13 & 30 & 60 & - & 10 & 0,6 & 0,002 \\
\hline 14 & 40 & 50 & - & 10 & 0,59 & 0,002 \\
\hline 15 & 50 & 40 & - & 10 & 0,57 & 0,002 \\
\hline
\end{tabular}

From uniformly mobile concrete mixtures size were molded the samples of 40x40x160 $\mathrm{mm}$. On the third day, the samples were formed and placed in a normal hardening chamber. After 28 days of normal hardening, the samples were dried to constant weight and tested for bending and compression according to a standard procedure. The results are shown in Table 2.

Table 2. Physico-mechanical characteristics and coefficients of constructive quality (CCQ) of light fine-grained concrete.

\begin{tabular}{|c|c|c|c|c|c|c|}
\hline \multirow{2}{*}{$\begin{array}{c}\text { No. } \\
\text { composition }\end{array}$} & \multicolumn{2}{|c|}{ Average density, $\mathrm{kg} / \mathrm{m}^{3}$} & \multirow{2}{*}{ Humidity, } & \multicolumn{2}{|c|}{ Strength, MPa } & \multirow{2}{*}{$\begin{array}{c}\mathrm{CCQ}=\mathrm{R} \\
\end{array}$} \\
& Wet & Dry & & $\begin{array}{c}\text { Unnder } \\
\text { compression }\end{array}$ & In bending & $\rho_{\mathrm{cp}}$ \\
\hline 1 & 1500 & 954 & 57,23 & 9,43 & 1,6 & 9,89 \\
\hline 2 & 1463 & 935 & 56,47 & 14,0 & 1,93 & 14,97 \\
\hline 3 & 1509 & 980 & 54,00 & 14,85 & 1,77 & 15,15 \\
\hline 4 & 1432 & 894 & 60,18 & 6,9 & 1,21 & 7,72 \\
\hline
\end{tabular}




\begin{tabular}{|c|c|c|c|c|c|c|}
\hline 5 & 1499 & 961 & 56,00 & 14,18 & 2,28 & 14,76 \\
\hline 6 & 1544 & 1004 & 53,80 & 10,84 & 1,84 & 10,8 \\
\hline 7 & 1446 & 943 & 53,34 & 11,24 & 2,28 & 11,92 \\
\hline 8 & 1501 & 984 & 52,24 & 14,58 & 2,07 & 14,82 \\
\hline 9 & 1509 & 1005 & 50,15 & 13,14 & 2,01 & 13,08 \\
\hline 10 & 1432 & 932 & 53,65 & 8,71 & 1,98 & 9,35 \\
\hline 11 & 1479 & 964 & 53,42 & 10,43 & 2,34 & 10,82 \\
\hline 12 & 1487 & 983 & 51,27 & 12,8 & 1,8 & 13,02 \\
\hline 13 & 1461 & 960 & 52,20 & 10,23 & 2,12 & 10,66 \\
\hline 14 & 1527 & 1006 & 51,80 & 14,17 & 2,15 & 14,09 \\
\hline 15 & 1522 & 1014 & 50,10 & 14,67 & 2,02 & 14,47 \\
\hline
\end{tabular}

It can be seen from Table 2 that an increase in the amount of microsilica in a concrete mixture leads to a decrease in the mechanical characteristics of fine-grained concrete. The introduction of $10 \%$ of the mass of solid components into the composition of chalk MTD-2 makes it possible to increase the compressive strength of concrete by $4 \div 19 \%$ and the bending strength by $7 \div 42.5 \%$; with the addition of chalk CALCITEC V/40S, the compression ratio was from 1 to $8 \%$ and with bending - from 11 to $32.5 \%$ [23].

Further studies were continued with composition No. 3 (Table 2), which has the largest coefficient of constructive quality.

To study the effect of the Portland cement brand on the strength properties of fine-grained concrete from concrete mixtures on different binders (Table 3), samples of 40x40x160 mm were made. After 28 days of normal hardening, the samples were dried to constant weight and tested for bending and compression according to a standard procedure. The test results are shown in Figures 1 and 2.

Table 3. Compositions of fine-grained concretes made on different binders.

\begin{tabular}{|c|c|c|c|c|c|}
\hline \multirow{2}{*}{$\begin{array}{c}\text { No. } \\
\text { composition }\end{array}$} & \multicolumn{5}{|c|}{ Solids content, \% by weight } \\
\cline { 2 - 6 } & PC 400 D20 & PC 600 & MK & Water & Hyperplasticizer \\
\hline 1 & 50 & - & 50 & 0,6 & 0,002 \\
\hline 2 & - & 50 & 50 & 0,6 & 0,002 \\
\hline
\end{tabular}

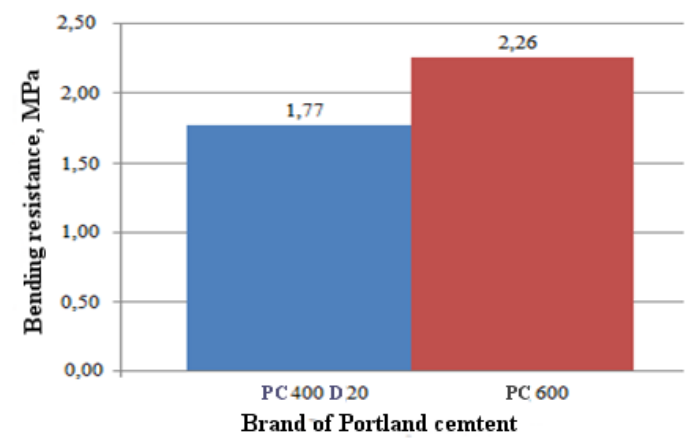

Fig. 1. Dependence of the flexural strength of light fine-grained concrete (Portland cement). 


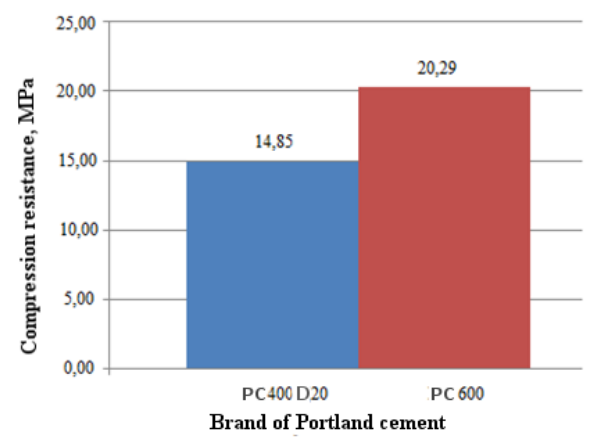

Fig. 2. Dependence of the compressive strength of fine fine-grained concrete (Portland cement).

It can be seen from Figures 1 and 2 that the use of high-strength Portland cement in the composition of light fine-grained concrete contributed to an increase in its strength characteristics: bending strength increased by $28 \%$, compressive strength - by $37 \%$.

To determine the influence of the amount of basalt fiber on the strength of bending finegrained concrete from concrete mixes with different percentage of basalt fiber (from $0.125 \%$ to $0.5 \%$ of the mass of solids), samples of $40 \times 40 \times 160 \mathrm{~mm}$ were made. After 28 days of normal hardening, the samples were dried to constant weight and tested for bending according to a standard procedure. The test results are shown in Figure 3.

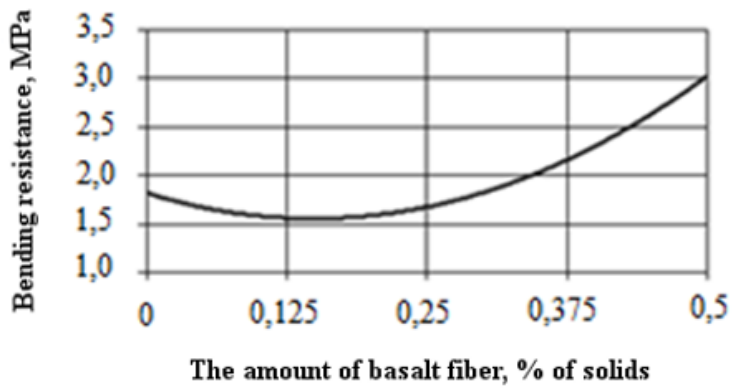

Fig. 3. Dependence of the flexural strength of light fine-grained concrete on the amount of basaltic fiber.

From the graph shown in Figure 3, it can be seen that the introduction of basalt fiber in an amount of $0.5 \%$ of the mass of solids contributes to an increase in strength when bending light fine-grained concrete to $70 \%$.

It was experimentally established that:

- The optimum ratio of Portland cement to microsilica is 1: 1 ;

- The addition of chalk in an amount of $10 \%$ of the mass of solids to the composition of concrete mixtures has a positive effect on the mechanical properties of the finished concrete;

- The introduction of a dispersive-reinforcing additive (basalt fiber) in an amount of $0.5 \%$ of the mass of solids contributes to an increase in the bending strength of fine-grained concrete to $70 \%$.

The replacement of a sandy aggregate with microsilica by fine-grained concrete leads to a decrease in its average density to $900 \div 1040 \mathrm{~kg} / \mathrm{m}^{3}$, which is approximately two times lower 
than the average density of fine-grained concrete on natural sand, which, according to the author's data [1], is $2058 \mathrm{~kg} / \mathrm{m}^{3}$.

And in conclusion I would like to note that the high-mobility concrete mix proposed by the authors, contains the following (\%): (a) white Portland cement CEM I 52.5R - 50; (b) microsilica - 50; (c) basalt fiber-0,5; (d) hyperplasticizer "MC-Power-Flow-3100" - 0,002.

\section{References}

1. Yu.V. Degtev, the dissertation author's abstract on competition of a scientific degree of the Cand.Tech.Sci., Self-compacting concretes on composite astringents for small architectural forms, 218 p. (2015)

2. T. A. Nizina, A. S. Balykov, V. V. Volodin и др., MCE, Fiber fine-grained concretes with polyfunctional modifying additives, c.73-83 (2017)

3. Oliver Fenyvesi, Bence Jankus, EJSBCM, 66-70 (2015)

4. R. Fediuk, A. Pak, D. Kuzmin, ICCATS, Fine-Grained Concrete of Composite Binder, (2017)

5. Y. N. Ogurtsova, V. V. Strokova, M. V. Labuzova, ICCATS, (2017)

6. Edyta Pawluczuk, EISEE, 108-118 (2017)

7. Roy Nir Lieberman, Yaniv Knop, Xavier Querol и др., JHM, 1043-1056 (2018)

8. D. Oreshkin, V. Semenov, T. Rozovskaya, 25th RPSSTFCE, 638-643 (2016)

9. Shiping Yin, Bo Wang, Fei Wang и др., JIT, 1616-1632 (2017)

10. R. V. Lesovik, M. S. Ageeva, V. G. Golikov, Yu. V. Fomenko, SM, 66-68 (2005)

11. I. V. Mal'tseva, E. V. Maltsev, NO, 120-123 (2015)

12. V. N. Vyrova, V. F. Khritanakov, I. V. Belan, M. A. Pichugin, PMST-2014, 330-335 (2014)

13. H. A. Miari, the dissertation author's abstract on competition of a scientific degree of the Cand.Tech.Sci., Fine-grained concrete from high-mobility concrete mixtures with use of industrial wastes and local raw materials (1992)

14. S. M. Tolchin, the dissertation author's abstract on competition of a scientific degree of the Cand.Tech.Sci., Fine-grained concretes on combined aggregates from industrial wastes (1997)

15. Z. Kh. Ismailova, Effective fine-grained concrete with an organomineral additive on the basis of ash and slag mixtures (2008)

16. V. G. Golikov, the dissertation author's abstract on competition of a scientific degree of the Cand.Tech.Sci., Fine-grained concrete for small architectural forms on the basis of technogenic sands KMA (2005)

17. S. A. Murtazaev, Z. Kh. Ismailova, S. A. Aliev, B. T. Murtazaev, EPR, 23-25 (2011)

18. E. A. Kasper, O. S. Bochkareva, SMT, 135-138 (2015)

19. T. A. Nizina, A. N. Ponomarev, A. S. Balykov, SM, 68-72 (2016)

20. I. A. Bykov ISDRPK, 430-432 (2017)

21. V. V. Shcherba, A. A. Shishkin, A. A. Shishkina, CNSG, 41-48 (2014)

22. A. A. Baranova, A. A. Bobrova, K. N. Rudykh, Modern Technologies and Scientific and Technical progress, 108-109 (2017) 
23. A. A. Baranov, M. V. Badenikova, A. A. Bobrov, K. N. Rudykh, AnGTU Herald, 147-150 (2017) 